\title{
PENGARUH KOMPETENSI DAN LINGKUNGAN KERJA TERHADAP KINERJA KARYAWAN PADA PT. SMART MULTI FINANCE CABANG SANGATTA
}

\author{
Inda Khaerani, Meita Sondang Riski \\ Sekolah Tinggi Ilmu Ekonomi Nusantara Sangatta \\ Email : indakhaerani08@gmail.com \\ meitasondang@yahoo.com
}

\begin{abstract}
Abstrak
Tujuan dari penelitian ini adalah untuk menganalisis pengaruh kompetensi, lingkungan kerja terhadap kinerja karyawan pada PT. Smart Multi Finance Cabang Sangatta. Penelitian ini menggunakan metode kuantitatif yakni menguji dan menganalisis data dengan perhitungan angka-angka dan kemudian menarik kesimpulan atas pengujian tersebut. Objek yang diteliti adalah keseluruhan karyawan pada PT. Smart Multi Finance Cabang Sangatta yang berjumlah 34 orang. Dari hasil analisa diketahui bahwa : pertama, terdapat pengaruh yang signifikan antara kompetensi terhadap kinerja karyawan pada PT. Smart Multi Finance Cabang Sangatta; kedua, terdapat pengaruh yang signifikan antara lingkungan kerja terhadap kinerja karyawan pada PT. Smart Multi Finance Cabang Sangatta; ketiga, berdasarkan uji $F$ terdapat pengaruh yang signifikan antara kompetensi dan lingkungan kerja terhadap kinerja karyawan pada PT. Smart Multi Finance Cabang Sangatta.
\end{abstract}

Kata kunci : Kompetensi, Lingkungan Kerja, Kinerja Karyawan

\section{PENDAHULUAN}

PT. Smart Multi Finance adalah perusahaan yang bergerak di bidang pembiayaan modal kerja dan multiguna dengan agunan BPKB kendaraan motor ataupun mobil. Setiap perusahaan memiliki tujuan untuk mendapatkan keuntungan begitu juga dengan PT. Smart Multi Finance yang memiliki tujuan untuk mendapat keuntungan. PT. Smart Multi Finance dapat mencapai tujuannya jika memiliki sumber daya manusia yang berkompeten dan berkualitas, jadi keberhasilan suatu perusahaan tergantung pada sumber daya manusianya.

Sumber daya manusia merupakan aset yang paling berharga yang dimiliki oleh suatu perusahaan, sumber daya manusia juga mempunyai peran utama dalam setiap perusahaan yaitu sebagai perencana, pelaksana dan pengendali di berbagai kegiatan perusahaan, (Efendi, et al., 2017). PT. Smart Multi Finance memiliki 34 karyawan (sumber daya manusia) dan terbagi i menjadi beberapa divisi. Tanpa adanya peran sember daya manusia tersebut segala kegiatan yang ada di perusahaan tidak akan berjalan secara efektif dan efisien dalam mencapai tujuannya. Oleh karena itu sangat penting bagi perusahaan untuk mengelola sumber daya manusianya dengan baik agar menjadi sumber daya manusia yang kompeten dalam bekerja, seperti dengan memberikan pelatihan, rasa nyaman dan aman dalam bekerja. 
Kompetensi sumber daya manusia yang memadai dapat mendorong kinerja karyawan menjadi lebih baik, dengan demikian kompetensi menjadi sangat berguna untuk membantu perusahaan meningkatkan kinerja. Kompetensi karyawan memiliki pengaruh pada kinerja, baik itu kinerja individu maupun organisasi. Perusahaan diharuskan mencari karyawan yang berkualitas, berpotensi dan menempatkan posisinya pada kompetensinya. Tingkat pendidikan karyawan PT. Smart Multi Finance Cabang Sangatta sebanyak $82 \%$ adalah SLTA dan sisanya Sarjana sebanyak $18 \%$.

Lingkungan kerja PT. Smart Multi Finance Cabang Sangatta sejauh ini masih dirasakan karyawannya kurang nyaman karena kondisi gedung yang kurang luas, ruang kerja khususnya di ruangan operasional yang berisi banyakt orang namun ruangannya sangat kecil dan masih dipenuhi dengan barang di dalam ruangan tersebut. Ruangan yang sempit tersebut membuat karyawan merasa kurang nyaman dalam bekerja, tidak bebas dalam bergerak. Penataan barang tidak tertata dengan rapi dan kondisi ruangan panas dikarenakan AC tidak berfungsi dengan baik dan tidak ada ventilasi udara.

\section{KAJIAN TEORI}

\section{Kinerja}

Arti kata kinerja berasal dari kata-kata job performance dan di sebut juga actual performance atau prestasi kerja atau prestasi sesungguhnya yang telah di capai oleh seseorang karyawan (Moeheriono,2012:69). Mangkunegara (2015:67) menjelaskan pengertian kinerja adalah hasil kerja secara kualitas dan kuantitas yang dicapai oleh seorang pegawai dalam melaksanakan tugasnya sesuai dengan tanggung jawab yang diberikan kepadanya. Sedangkan Afandi (2016:83) menjelaskan kinerja adalah hasil kerja yang dapat dicapai oleh seseorang atau kelompok orang dalam suatu perusahaan sesuai dengan wewenang dan tanggung jawab masing-masing dalam upaya pencapaian tujuan organisasi secara illegal, tidak melanggar hukum dan tidak bertentangan dengan moral dan etika.

\section{Kompetensi}

Edison et al. (2016) menjelaskan kompetensi adalah kemampuan individu untuk melaksanakan suatu pekerjaan dengan benar dan memiliki keunggulan yang didasarkan pada hal-hal yang menyangkut pengetahuan (knowledge), keahlian (skill), dan sikap (attitude). 
Menurut George Klemp (dalam Edison et al., 2016:143) kompetensi adalah karakteristik yang mendasari seseorang yang menghasilkan pekerjaan yang efektif dan/atau kinerja yang unggul.

\section{Lingkungan Kerja}

Menurut Sedarmayanti (dalam Rahmawanti, 2014:3), definisi lingkungan kerja adalah keseluruhan alat perkakas dan bahan yang dihadapi, lingkungan sekitarnya di mana seseorang bekerja, metode kerjanya, serta pengaturan kerjanya baik sebagai perseorangan maupun kelompok.

Menurut Afandi (2016:51), lingkungan kerja adalah sesuatu yang ada dilingkungan para pekerja yang dapat memengaruhi dirinya dalam menjalankan tugas seperti temperatur, kelembaban, ventilasi, penerangan, kegaduhan, kebersihan tempat kerja dan memadai tidaknya alat-alat perlengkapan kerja. Sedangkan menurut Sunyoto (2015:38), lingkungan kerja merupakan komponen yang sangat penting ketika karyawan melakukan aktivitas bekerja. Dengan memperhatikan lingkungan kerja yang baik atau menciptakan kondisi kerja yang mampu memberikan motivasi untuk bekerja, maka akan membawa pengaruh terhadap kinerja karyawan dalam bekerja.

Menurut Sedarmayanti (2011:26) lingkungan kerja terbagi menjadi dua yaitu sebagai berikut

a. Lingkungan kerja fisik adalah semua keadaan berbentuk fisik yang terdapat di sekitar tempat kerja yang dapat memengaruhi pegawai baik secara langsung maupun tidak langsung. Lingkungan kerja fisik dapat dibagi dalam dua kategori yakni : lingkungan yang langsung berhubungan dengan pegawai, misalnya: pusat kerja, meja, kursi dan sebagainya. Lingkungan perantara atau lingkungan umum juga disebut lingkungan kerja yang mempengaruhi kondisi manusia, misalnya : temperatur, kelembaban, sirkulasi udara, pencahayaan, warna, dan lain-lain.

b. Lingkungan kerja nonfisik adalah semua keadaan yang terjadi yang berkaitan dengan hubungan kerja, baik hubungan dengan atasan maupun hubungan sesama rekan kerja, ataupun hubungan dengan bawahan.

\section{METODE PENELITIAN}

Penelitian ini menggunakan metode kuantitatif dengan analisis regresi linear berganda dengan menggunakan SPSS versi 25. Teknik sampling dalam penelitian ini menggunakan 
teknik sampling jenuh yang dimana populasinya yaitu keseluruhan karyawan pada PT. Smart Multi Finance Cabang Sangatta atau sebanyak 34 karyawan dan sampelnya keseluruhan dari jumlah populasi yang ada yaitu sebanyak 34 karyawan. Teknik pengumpulan data menggunakan kuesioner dengan sumber datanya berasal dari responden dan juga dokumen perusahaan.

\section{HASIL DAN PEMBAHASAN}

Hasil analisis regresi linear berganda menunjukkan bahwa besarnya nilai Standardized Coefficients Beta masing-masing variabel yaitu kompetensi $\left(\mathrm{X}_{1}\right)$ terhadap kinerja karyawan (Y) sebesar 0,427 dan lingkungan kerja $\left(\mathrm{X}_{2}\right)$ terhadap kinerja karyawan sebesar 0,595. Dari nilai Standardized Coefficients Beta masing-masing tersebut memberikan arti bahwa setiap perubahan atau peningkatan variabel dapat menyebabkan pengaruh yang berdampak positif terhadap kinerja karyawan. Dampak positif terjadi pada variabel kompetensi $\left(\mathrm{X}_{1}\right)$ dan lingkungan kerja $\left(\mathrm{X}_{2}\right)$, dapat diformulasikan dalam persamaan regresi sebagai berikut : $\mathrm{Y}=$ $0,427\left(\mathrm{X}_{1}\right)+0,595\left(\mathrm{X}_{2}\right)$

Persamaan tersebut dapat diartikan bahwa setiap perubahan atau peningkatan pada masing-masing variabel independen kompetensi $\left(\mathrm{X}_{1}\right)$ dan $\left(\mathrm{X}_{2}\right)$ berpengaruh juga terhadap perubahan atau peningkatan kinerja karyawan (Y).

Tabel 1

Uji Koefisien Determinasi

\begin{tabular}{|l|r|r|r|r|r|}
\hline Model & $\mathrm{R}$ & $\begin{array}{c}\mathrm{R} \\
\text { Square }\end{array}$ & $\begin{array}{c}\text { Adjuste } \\
\mathrm{d} \text { R } \\
\text { Square }\end{array}$ & $\begin{array}{c}\text { Std. Error } \\
\text { of the } \\
\text { Estimate }\end{array}$ & $\begin{array}{r}\text { Durbin- } \\
\text { Watson }\end{array}$ \\
\hline 1 &, $856^{\mathrm{a}}$ &, 732 &, 715 &, 218 & 1,394 \\
\hline
\end{tabular}

Sumber : Pengolahan Data SPSS, 2021

Tabel 1 menunjukkan bahwa nilai korelasi $R$ sebesar 0,856 dan koefisien diterminasi $R$ Square sebesar 0,732 memberikan gambaran bahwa hubungan antara variabel kompetensi $\left(\mathrm{X}_{1}\right)$ dan lingkungan kerja $\left(\mathrm{X}_{2}\right)$ secara bersama-sama terhadap kinerja karyawan (Y) pada PT. Smart Multi Finance Cabang Sangatta tergolong kuat. Pengaruh yang dijelaskan oleh variabel kompetensi $\left(\mathrm{X}_{1}\right)$ dan lingkungan kerja $\left(\mathrm{X}_{2}\right)$ secara bersama-sama terhadap kinerja karyawan sebesar $73,2 \%$, sisanya $26,8 \%$ dijelaskan oleh variabel-variabel lain yang tidak masuk dalam model penelitian. 
Tabel 2

Uji t Variabel Penelitian

\begin{tabular}{|c|c|c|c|c|c|c|}
\hline \multirow{2}{*}{\multicolumn{2}{|c|}{ Model }} & \multicolumn{2}{|c|}{$\begin{array}{l}\text { Unstandardize } \\
\text { d Coefficients }\end{array}$} & \multirow{2}{*}{$\begin{array}{c}\begin{array}{c}\text { Standardize } \\
\mathrm{d}\end{array} \\
\text { Coefficients }\end{array}$} & \multirow[t]{2}{*}{$\mathrm{t}$} & \multirow[t]{2}{*}{ Sig. } \\
\hline & & B & $\begin{array}{l}\text { Std. } \\
\text { Error }\end{array}$ & & & \\
\hline \multirow{3}{*}{1} & (Constant & 1,018 & ,273 & & 3,735 & ,001 \\
\hline & $\mathrm{X} 1$ & ,321 & ,076 & ,427 & 4,246 & ,000 \\
\hline & $\mathrm{X} 2$ & ,359 & ,061 & ,595 & 5,909 & ,000 \\
\hline
\end{tabular}

Sumber : Pengolahan Data SPSS, 2021

Tabel 2 menunjukkan bahwa besarnya nilai thitung untuk variabel kompetensi adalah

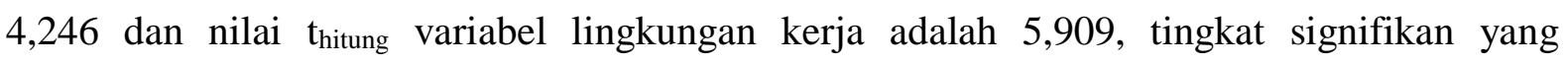
digunakan adalah 0,05 . Nilai $t_{\text {tabel }}$ dapat diketahui melalui tabel statistik pada tingkat 0,05 $(5 \%)$. Besarnya $t_{\text {tabel }}$ dapat diperoleh dengan cara $(\mathrm{df})=\mathrm{n}-\mathrm{k}$ dalam hal ini $\mathrm{n}$ adalah jumlah sampel dan k adalah jumlah variabel. Pada kasus ini besarnya df dapat dihitung 34-3 atau df $=31$ dengan alpha 0,05 didapat $\mathrm{t}_{\text {tabel }}=1,69552$. Jadi dapat disimpulkan bahwa nilai $t_{\text {hitung }}$ dari masing-masing variabel lebih besar dari nilai $t_{\text {tabel }}$ yang artinya kompetensi berpengaruh positif dan signifikan terhadap kinerja karyawan pada PT. Smart Multi Finance Cabang Sangatta begitu juga dengan lingkunga kerja berpengaruh positif dan signifikan terhadap kinerja karyawan pada PT. Smart Multi Finance Cabang Sangatta.

Tabel 3

Uji F (Simultan)

\begin{tabular}{|l|l|r|r|r|r|r|}
\hline \multicolumn{2}{|l|}{ Model } & $\begin{array}{c}\text { Sum of } \\
\text { Square } \\
\text { s }\end{array}$ & df & $\begin{array}{c}\text { Mean } \\
\text { Square }\end{array}$ & F & Sig. \\
\hline 1 & Regression & 4,035 & 2 & 2,017 & 42,375 &, $000^{\mathrm{b}}$ \\
\cline { 2 - 7 } & Residual & 1,476 & 31 &, 048 & & \\
\cline { 2 - 7 } & Total & 5,511 & 33 & & & \\
\hline \multicolumn{2}{|l|}{ a. Dependent Variable: Y } \\
\hline \multicolumn{2}{|l|}{ b. Predictors: (Constant), X2, X1 } \\
\hline
\end{tabular}

Sumber : Pengolahan Data SPSS, 2021 
Hasil dari $F_{\text {tabel }}$ menggunakan taraf nyata 5\% adalah sebagai berikut: $(k-1):(n-k)=3-1=2$ :

$(34-3)=31$

Ftabel $=(\alpha ; \mathrm{k} ; \mathrm{n}-\mathrm{k}-1)$

Ftabel $=0,05: 2):(34-2-1)$

Ftabel $=0,05: 2: 31$

Ftabel $=3,30$

Tabel 3 menunjukkan bahwa nilai $F_{\text {hitung }} 42,375 \geq F_{\text {tabel }} 3,30$ pada signifikansi $0,00 \leq$ 0,05, maka hipotesis diterima. Hal ini menunjukkan bahwa adanya pengaruh kompetensi $\left(\mathrm{X}_{1}\right)$ dan lingkungan kerja $\left(\mathrm{X}_{2}\right)$ secara bersama-sama atau simultan terhadap kinerja karyawan $(\mathrm{Y})$ pada PT. Smart Multi Finance Cabang Sangatta. Dapat disimpulkan bahwa kompetensi dan lingkungan kerja secara simultan berpengaruh terhadap kinerja karyawan pada PT. Smart Multi Finance Cabang Sangatta.

\section{PENUTUP}

\section{Kesimpulan}

Berdasarkan dari hasil penelitian dapat ditarik kesimpulan yaitu sebagai berikut :

a. Kompetensi berpengaruh terhadap kinerja karyawan pada PT. Smart Multi Finance Cabang Sangatta, hal ini dapat dibuktikan dari hasil penelitian yang menyatakan bahwa hipotesis pertama terdapat pengaruh kompetensi terhadap kinerja karyawan diterima (terbukti) sehingga penulis berkesimpulan bahwa semakin tinggi kompetensi karyawan maka semakin baik juga kinerja karyawan pada PT. Smart Multi Finance Cabang Sangatta.

b. Lingkungan kerja berpengaruh terhadap kinerja karyawan pada PT. Smart Multi Finance Cabang Sangatta, hal ini dapat dibuktikan dari hasil penelitian yang menyatakan hipotesis kedua terdapat pengaruh lingkungan kerja terhadap kinerja karyawan diterima (terbukti) sehingga penulis berkesimpulan bahwa semakin baik lingkungan kerja karyawan maka semakin baik juga kinerja karyawan pada PT. Smart Multi Finance Cabang Sangatta.

c. Kompetensi dan lingkungan kerja secara simultan berpengaruh terhadap kinerja karyawan pada PT. Smart Multi Finance Cabang Sangatta, hal ini dapat dibuktikan dari hasil penelitian yang menyatakan hipotesis tiga terdapat pengaruh kompetensi dan lingkungan kerja bersama-sama diterima (terbukti) sehingga penulis berkesimpulan 
bahwa semakin tinggi kompetensi dan lingkungan kerjanya semakin baik juga maka semakin baik juga kinerja karyawan pada PT. Smart Multi Finance Cabang Sangatta, jika kompetensi dan lingkungan kerja tidak baik maka kinerja karyawan juga tidak akan baik.

\section{Saran}

a. Bagi PT. Smart Multi Finance Cabang Sangatta yaitu : berdasarkan perhitungan mengunakan loading faktor dapat diketahui komponen terendah pada variabel kompetensi adalah indikator watak, jadi perusahaan perlu meningkatkan lagi upaya pemberian dorongan untuk melatih karakteristik mental karyawan agar karyawan lebih mematuhi lagi tentang perusahaan begitu juga dengan semua indikator pada lingkungan kerja. Perusahaan juga perlu meningkatkan lagi upaya untuk meningkatkan kompetensi karyawannya. Berdasarkan perhitungan mengunakan loading faktor dapat diketahui komponen terendah pada variabel lingkungan kerja adalah indikator penerangan, jadi perusahaan perlu meningkatkan lagi tingkat penerangan di lingkungan pekerjaan agar karyawan bisa bekerja dengan baik begitupun dengan semua indikator pada lingkungan pekerjaan agar pekerjaan karyawan menjadi lebih baik sesuai dengan yang diharapkan perusahaan. Perusahaan perlu melakukan perbaikan pada lingkungan tempat kerja karyawan agar karyawan bisa lebih nyaman lagi dalam bekerja.

b. Untuk peneliti selanjutnya dapat mengembangkan penelitian ini dengan cara : menggunakan metode penelitian yang berbeda dengan penelitian ini untuk menguji sejauh mana pengaruh yang diberikan variabel independen terhadap kinerja karyawan, mengeksplorasi variabel independen yang akan digunakan untuk menguji kinerja karyawan, baik dengan penambahan variabel lain atau bahkan mengganti variabel yang ada dalam penelitian ini.

\section{DAFTAR PUSTAKA}

Afandi. 2016. Concept and Indicator Human Resourcer Management, Yogyakarta : Deepublish.

Edison dkk. 2016. Manajemen Sumber Daya Manusia. Bandung : Alfabeta.

Efendi et al. 2017. Pengaruh Kompetensi dan Lingkungan Kerja Terhadap Kinerja Karyawan Pada Bagian Produksi Perusahaan Rokok Adi Bungsu Malang. Jurnal Reset Manajemen, Fakultas Ekonomi Unisba, Malang.

Mangkunegara. 2015. Sumber Daya Manusia Perusahaan. Cetakan kedua belas. Bandung : PT. Remaja Rosdakarya. 
Moeheriono. 2012. "Pengukuran Kinerja Berbasis Kompetensi". Jakarta : Raja Grafindo Persada.

Rahmawanti. 2014. Sumber Daya Manusia dan Produktivitas Kerja. Jakarta : Mandar Maju. Sedarmayanti. 2011. Manajemen Sumber Daya Manusia. Reformasi Birokrasi dan Manajemen Pegawai Negeri Sipil, Cetakan Kelima, Bandung : PT Refika Aditama.

Sunyoto, Danang. 2015. Penelitian Sumber Daya Manusia. Jakarta: Buku Seru.

Timple, A. D. 2000. Produktivitas, Seri Manajemen Sumber Daya Manusia. Jakarta :Elex Media Komputindo. 